\title{
High Shear Granulation
}

National Cancer Institute

\section{Source}

National Cancer Institute. High Shear Granulation. NCI Thesaurus. Code C113011.

The use of a series of integrated steps whereby a dry powder is conditioned by wetting, or is melted, to form a plasticized mass that with the aid of high shear forces yields relatively dense particles. 